\title{
Implementación de buenas prácticas en alimentación bovina en la granja del colegio del Municipio de EI Dorado Meta
}

\author{
Implementation of good practices in bovine feeding in the farm of the school \\ of the municipality of EI Dorado Meta
}

\section{Implementação de boas práticas em alimentação bovina na fazenda da} escola do município de El Dorado Meta

\author{
Bernal Lizarazo Johan Sebastián ${ }^{1}$ y Fernández Manrique José ${ }^{2}$ \\ ${ }^{1}$ Medico Veterinario y Zootecnista, Universidad de los Llanos y \\ ${ }^{2}$ Medico Veterinario, MSc, Docente Universidad de los Llanos. \\ johan.bernal@unillanos.edu.co
}

Recibido 10 de febrero 2020, Aceptado 23 de octubre 2021

\section{RESUMEN}

Debido al conflicto armado en algunas de nuestras regiones, era imposible trabajar algunas zonas rurales con un alto potencial para un sistema de producción bovina, el objetivo de este proyecto fue promover a los campesinos, productores, docentes y jóvenes de la región del Dorado en el fortalecimiento del sector rural, mediante la implementación de las buenas prácticas en alimentación bovina con la ganadería de la Institución Educativa El Dorado, se tomaron seis muestras de sangre y seis muestras de material fecal de los animales, se tomaron muestras de suelo en los potreros de la granja para análisis físico-químico, Muestras de agua donde consumían los animales para análisis físico-químico y microbiológico. Las variables se analizaron mediante la estadística descriptiva. Al examen clínico, se encontró condición corporal en promedio de 3 , infestación marcada de ectoparásitos (Garrapatas y miasis). En el análisis de los cuadros hemáticos se evidencio 5 animales con aumento en la concentración de hemoglobina corpuscular media, 2 animales con leucocitosis y linfocitosis, 4 animales con eosinofilia. En la química sanguínea todos los animales presentaron glucosa baja, globulinas altas, además se encontró variación en la relación Ca-P. En el coprológico 3 animales presentaron anaplasmosis. El agua presento anormalidades en los parámetros microbiológicos. 
Los suelos son oxisoles, francos arenosos, con deficiencias en materia orgánica, $\mathrm{pH}$ y nitrógenos totales. Mejorando la calidad del agua y del suelo podemos tener mejores pastos. Mejorando la sanidad mayor aprovechamiento de los alimentos, para luego aplicar estrategias que mejoren la producción de forraje verde, establecimiento correcto de praderas mejoradas, uso adecuado de abonos y fertilizantes, adecuada rotación de potreros, y el establecimiento de métodos de conservación de forrajes como el ensilaje y el heno.

Palabras clave: Buenas prácticas en alimentación, conflicto, pastos, producción bovina, sector rural.

\section{ABSTRACT}

Due to the armed conflict in some of our regions, it was impossible to work in some rural areas with a high potential for a bovine production system. The objective of this project was to promote the farmers, producers, teachers and youth of the Dorado region in the strengthening of the rural sector, through the implementation of good practices in bovine feeding with the livestock of the Educational Institution El Dorado, six blood samples and six samples of fecal material were taken from the animals, soil samples were taken in the paddocks of the farm for physical-chemical analysis, Water samples where the animals consumed for physical-chemical and microbiological analysis. Variables were analyzed using descriptive statistics. Upon clinical examination, body condition was found on average of 3 , marked infestation of ectoparasites (ticks and myiasis). The analysis of the blood pictures revealed 5 animals with an increase in the concentration of mean corpuscular hemoglobin, 2 animals with leukocytosis and lymphocytosis, 4 animals with eosinophilia. In blood chemistry, all the animals presented low glucose, high globulins, and a variation in the Ca-P ratio was also found. In the stool 3 animals presented anaplasmosis. The water presented abnormalities in the microbiological parameters. The soils are oxisols, sandy loams, with deficiencies in organic matter, $\mathrm{pH}$ and total nitrogen. Improving the quality of water and soil we can have better pastures, improving sanitation, better use of food, and then apply strategies that improve the production of green forage, correct establishment of improved meadows, adequate use of 
fertilizers and fertilizers, adequate rotation of paddocks, and the establishment of forage conservation methods such as silage and hay.

Keywords: Good practices in food, conflict, pastures, bovine production, rural sector.

\section{RESUMO}

Devido ao conflito armado em algumas de nossas regiões, era impossível trabalhar em algumas áreas rurais com alto potencial para um sistema de produção de bovinos. O objetivo deste projeto era promover os agricultores, produtores, professores e jovens da região de Dorado na região. Fortalecimento do setor rural, por meio da implementação de boas práticas de alimentação bovina com os animais da Instituição Educacional El Dorado, seis amostras de sangue e seis amostras de material fecal foram retiradas dos animais, amostras de solo nos piquetes de a fazenda para análise físico-química, amostras de água onde os animais consumiram para análise físico-química e microbiológica. As variáveis foram analisadas por estatística descritiva. Ao exame clínico, foi encontrada uma condição corporal em média 3, infestação acentuada de ectoparasitas (carrapatos e miíase). A análise das imagens de sangue revelou 5 animais com aumento na concentração de hemoglobina corpuscular média, 2 animais com leucocitose e linfocitose, 4 animais com eosinofilia. Na química do sangue, todos os animais apresentaram glicose baixa, globulinas elevadas e também foi encontrada uma variação na razão Ca-P. Nas fezes, três animais apresentaram anaplasmose. A água apresentou anormalidades nos parâmetros microbiológicos. Os solos são latossolos, areia arenosa, com deficiências em matéria orgânica, $\mathrm{pH}$ e nitrogênio total. Melhorando a qualidade da água e do solo, podemos ter pastagens melhores, saneamento, melhor uso de alimentos e aplicar estratégias que melhorem a produção de forragem verde, estabelecimento correto de prados melhorados, uso adequado de fertilizantes e fertilizantes, rotação adequada de piquetes e estabelecimento de métodos de conservação de forragens, como silagem e feno. 
Palavras-chave: Boas práticas em alimentação, conflito, pastagem, produção bovina, setor rural.

\section{INTRODUCCIÓN}

Colombia como país productor de ganado localizado en la zona ecuatorial presentan un alto potencial para el desarrollo de la actividad ganadera, pero se han encontrado situaciones que determinan deficiencias en la alimentación del ganado, que afectan la eficiencia y productividad del eslabón de los productores primarios. Adicionalmente la transformación del manejo de praderas bajo estándares de eficiencia, productividad y armonía con el medio ambiente requiere de programas especiales y de acuerdo con CORPOICA, el manejo tradicional de las praderas representa a nivel nacional el $65.8 \%$ del área sembrada en pastos, el área en pradera tecnificada es el $31.9 \%$ y el área en pastos de corte representa el $2.4 \%$, dando una oportunidad de crecimiento para el sector.

A pesar de sus impactos ambientales y baja productividad, el sector ganadero en Colombia sigue teniendo un rol importante en la economía nacional porque genera alrededor del $19 \%$ del empleo agropecuario rural y cerca del $6 \%$ del empleo total nacional. Representa aproximadamente $1.4 \%$ del PIB nacional y $19 \%$ del PIB agrícola. En 2016 el inventario ganadero del país fue de 22.8 millones de cabezas. Un total de 3.7 millones de animales fueron sacrificados para producir 910000 toneladas de carne, mientras que la producción de leche fue de 6391 millones de litros. El consumo anual per cápita de productos ganaderos fue de $18.6 \mathrm{~kg}$ para la carne y 140 litros para la leche. La ganadería a pequeña escala predomina en el país, evidenciada por el hecho de que el $45 \%$ de las fincas tienen menos de 10 animales y el $81 \%$ controla solo el $25 \%$ del hato nacional y poseen menos de 50 animales por finca (Etter, 2018)

Las graves afectaciones de los recursos naturales y la actual crisis económica y social que atraviesan diversos países han revitalizado el interés por lograr un desarrollo acelerado y sostenido de la agricultura, el cual solo se conseguirá en la medida en que las estrategias de producción sean congruentes con el uso racional del ecosistema. Bajo el nombre de sistemas agrosilvopastoriles (SASP) se agrupa 
un conjunto de técnicas de uso de la tierra que implica la combinación o asociación deliberada de un componente leñoso (forestal o frutal) con ganadería y/o cultivos en el mismo terreno, con interacciones significativas ecológicas y/o económicas o solo necesariamente biológicas, entre los componentes (Iglesias et al., 2011).

Con la aplicación de las técnicas agroforestales, las actividades agrícolas y ganaderas adquieren un carácter permanente; su desarrollo no requiere de altos insumos, ya que el uso de la maquinaria es mínimo, ni tampoco se precisa de altas dosis de fertilizantes ni pesticidas para mantener el sistema de producción de forma sostenible. En este sentido, los sistemas agroforestales se presentan como un reto para la esfera agropecuaria, por ser una solución económicamente viable, socialmente aceptada y que no produce daños ambientales.

Otras estrategias para el uso óptimo de los recursos naturales son las denominadas Buenas Prácticas Ganaderas (BPG), se refieren a todas las acciones involucradas en el eslabón primario de la ganadería bovina, encaminadas al aseguramiento de la inocuidad de los alimentos carne y leche, la protección del medio ambiente y de las personas que trabajan en la explotación.

Dado que el país requiere mejorar el estatus sanitario de los productos que tienen un potencial exportador, para lograr la admisibilidad de la carne, leche y sus productos derivados, se identificó la necesidad de capacitar a los ganaderos para cumplir lo reglamentado por el ICA mediante los Decretos 1500 de 2007 y 616 de 2006, mediante las Resoluciones 2341 de 2007 y 3585 de 2008, respectivamente, para optar por la certificación de sus explotaciones (FEDEGAN, 2010).

El conocer la problemática del Municipio de El Dorado y Granada, permite elaborar propuestas y escenarios pilotos, para el desarrollo local, el cual será un laboratorio donde la comunidad, autoridades municipales, estudiantes y profesores podrán trabajar en equipo en soluciones para una mejor calidad de vida.

El propósito de este trabajo fue diseñar un plan estratégico aplicando las buenas prácticas en la alimentación del sistema de producción bovina en el colegio del Municipio de El Dorado Meta. Donde estudiantes de la modalidad pecuaria de la 
Institución Educativa de El Dorado, estudiantes de la Unillanos, productores de la región y comunidad general encuentren el modelo para desarrollar buenas prácticas en la alimentación bovina, en sus predios o proyectos productivos.

\section{METODOLOGÍA}

Geográficamente el Municipio de El Dorado está situado en la subregión del Piedemonte llanero, está ubicado al Noroccidente del departamento del Meta parte alta de la cuenca del río Ariari, que corresponde a la región Orinoquía. Forma parte del Parque Nacional de Sumapaz, con 1143.7 ha de este sistema geográfico. Territorialmente comprende la cabecera municipal El Dorado, Centros Poblados: San Isidro del Ariari y Pueblo Sánchez y catorce Veredas: Santa Rosa Alta, Santa Rosa Baja, Aguas Zarcas, La Isla, El Diamante, San José, La Meseta, Alto Cumaral, San Pedro, Caño Amarillo, Caño Leche, Palomarcado, La Esmeralda y La Cumbre.

El Municipio limita al noroccidente con el Municipio de Cubarral, al Suroccidente con el Municipio de El Castillo y al Oriente con el Municipio de San Martín. Posee una extensión total: $115 \mathrm{Km}^{2}$, temperatura media de $21^{\circ} \mathrm{C}$ y una altitud media de 550 msnm. La granja El Dorado se ubica en la vereda Pueblo Sánchez, la producción ganadera del colegio cuenta con una extensión aproximada de 6 hectáreas (Figura 1).

Como primer paso se realizó una charla en la Universidad de los Llanos sede Granada Meta, en la cual participaron el director del centro de producción ganadera del colegio del Dorado y ganaderos interesados de la región del Dorado y Granada Meta, a quienes se informó sobre el proyecto "Ética ambiental y bienestar animal estrategia de desarrollo rural en paz" énfasis en fortalecimiento de la producción bovina. Esto con el fin de generar una cooperativa de ganaderos de la región e indicándoles como se pensaba trabajar con ellos durante el proyecto.

Se aplicó una encuesta básica sobre información de sus predios a los ganaderos que participaron en la charla, y se seleccionaron 20 predios en total 10 fincas en El Dorado, incluyendo la Institución Educativa El Dorado y 10 fincas en Granada. Se 
realizaron visitas a esas 20 fincas y al colegio, donde se les recordó que procedimientos debían realizar en sus producciones y cómo ejecutarlos.

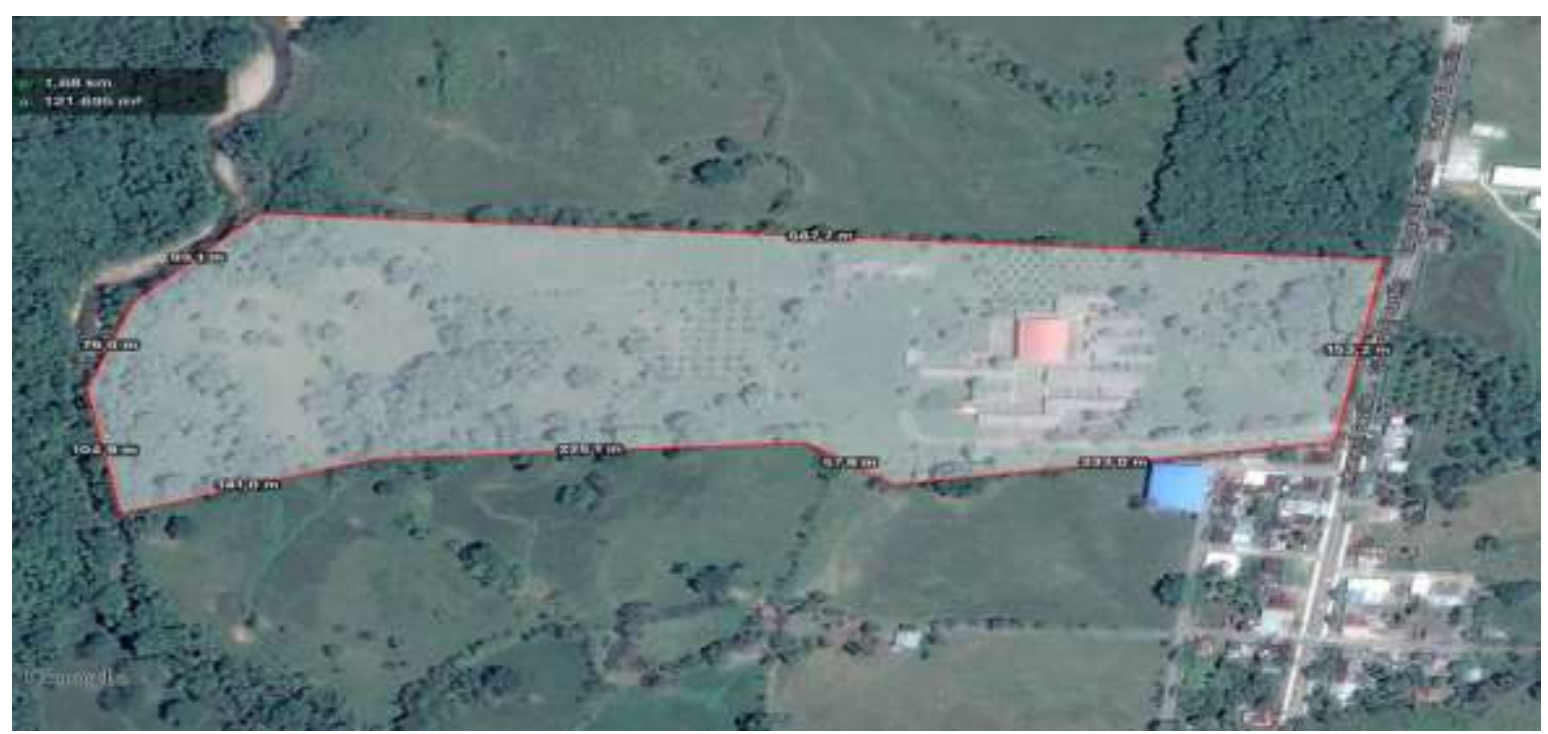

Figura 1 Ubicación satelital del área perteneciente a la IE EI Dorado. Google maps (2018).

En una primera visita se tomaron muestras de suelo y de agua en los potreros donde los animales de la producción bovina se alimentaban, posteriormente se llevaron a los laboratorios de la Universidad de los Llanos para su análisis.

En una segunda visita se seleccionaron en promedio de 7-10 animales por finca, la Institución Educativa El Dorado solo contaba en ese momento con 6 animales en producción. Al total de los animales seleccionados en todas las fincas se les realizó un examen general (Examen clínico), se tomaron muestras de sangre y materia fecal, para un posterior análisis en los respectivos laboratorios de la Universidad de los Llanos. En total se muestrearon 154 animales de las 20 fincas.

Las muestras de suelos y aguas se procesaron en los laboratorios del programa de ingeniería agronómica, y los análisis de sangre se evaluaron en el laboratorio de fisiología y parasitología del programa de medicina veterinaria y zootecnia. Se les realizó, cuadro hemático, química sanguínea, frotis sanguíneo. Con la materia fecal se realizó un estudio coprológico por medio de 3 modalidades "McMaster, Dennis y Bartman" para determinación de parásitos y sus huevos. 
Como último paso se recopiló toda la información, se analizaron los resultados con los propietarios de las fincas y docentes del colegio, logrando reconocer y aplicar diferentes estrategias y tecnologías sencillas que permiten entender y explotar de manera eficientemente los sistemas de producción bovina de doble propósito en la región.

\section{RESULTADOS Y DISCUSIÓN}

En la charla que se realizó con los ganaderos de la región del Dorado, Granada Meta y la IE El Dorado, y por medio de la aplicación de la encuesta, se caracterizaron los predios.

En el examen clínico encontramos que el promedio de la condición corporal de los animales era de 3 , sin embargo 2 animales presentaron una condición de 2.5 lo cual podía estar relacionado con cualquier factor como la alimentación, el manejo, problemas infecciosos bacterianos, virales, parasitarios, metabólicos 0 multifactoriales etc. (Tabla 1). Además, pudimos observar que la mayoría de los animales presentaban una infestación alta de ectoparásitos en la piel, como el nuche que es producido por la mosca Dermatobia hominis, Para lo cual se recomiendo realizar un manejo integrado de plagas que incluía: toma de muestras e identificación de los ectoparásitos, manejo adecuado de excretas para disminuir los criaderos de la mosca, evaluación de la eficacia de los biocidas, aplicación técnica de productos de acción sistémica como el crufomato o por baños por aspersión de metrifonato o cipermetrina.

Para las garrapatas se comienza con: identificación de la garrapata para determinación de ciclo de la garrapata, correcta rotación de los animales por los potreros, manejo adecuado de pasturas, evaluación de los biocidas y baños medicados con amidinas o amitraz.

Los parámetros de la línea roja del cuadro hemático mostraron que 5 de 6 animales presentaron un aumento en la concentración de hemoglobina corpuscular media $(\mathrm{MCHC})$ a pesar de que solo 1 mostró tener los eritrocitos altos (Tabla 2), lo cual puede estar asociado a deficiencias en el suministro de cobalto y relacionado con 
el déficit en la síntesis de Vitamina B12, también se dice que ese aumento puede estar relacionado con deficiencias en Vitamina B9 o A. Fólico, para lo cual se recomendó utilizar suplementos de Complejo B inyectados a todos los animales, y monitorear frecuentemente cada 30 días con otro cuadro hemático. Para el animal con eritrocitos altos se presume se encontraba deshidratado lo cual puede generar esa hemoconcentración debido a que varios factores de ese cuadro hemático estaban elevados, se sugirió revisar la disponibilidad del agua y que la esté consumiendo.

Tabla 1. Examen clínico general de los animales de la IE EI Dorado

\begin{tabular}{|c|c|c|c|c|c|c|c|c|c|}
\hline $\begin{array}{c}\text { Número } \\
\text { del } \\
\text { animal }\end{array}$ & Identificación & Sexo & Raza & Edad & Peso & Color & C:C & $\begin{array}{c}\text { Piel y } \\
\text { mucosas }\end{array}$ & $\begin{array}{l}\text { Digestivo/ } \\
\text { respiratorio/ } \\
\text { productivo }\end{array}$ \\
\hline 1 & $215-9$ & Hembra & $\begin{array}{l}\text { Jersey } \\
\text { cruzado }\end{array}$ & - & - & $\begin{array}{c}\text { Blanco } \\
\text { negro }\end{array}$ & 3 & $\begin{array}{c}\text { Nuche, } \\
\text { Garrapatas, } \\
\text { rosas } \\
\text { pálidas }\end{array}$ & N.E. \\
\hline 2 & Barcina & Hembra & Hereford & - & - & Barcina & 2.5 & $\begin{array}{c}\text { Nuche, } \\
\text { Garrapatas, } \\
\text { rosas } \\
\text { pálidas }\end{array}$ & N.E. \\
\hline 3 & 18JB & Hembra & $\begin{array}{l}\text { Jersey } \\
\text { cruzado }\end{array}$ & - & - & $\begin{array}{c}\text { Blanco } \\
\text { negro }\end{array}$ & 3 & $\begin{array}{c}\text { Nuche, } \\
\text { Garrapatas, } \\
\text { rosas } \\
\text { pálidas }\end{array}$ & N.E. \\
\hline 4 & 18JB negro & Hembra & $\begin{array}{l}\text { Mestiza } \\
\text { cebú }\end{array}$ & - & - & Negro & 2.5 & $\begin{array}{c}\text { Nuche, } \\
\text { Garrapatas, } \\
\text { rosas } \\
\text { pálidas }\end{array}$ & N.E. \\
\hline 5 & $\mathrm{JB}$ & Hembra & $\begin{array}{l}\text { Jersey } \\
\text { cruzado }\end{array}$ & - & - & Café & 3 & $\begin{array}{c}\text { Nuche, } \\
\text { Garrapatas, } \\
\text { rosas } \\
\text { pálidas }\end{array}$ & N.E. \\
\hline 6 & JB & Hembra & Mestiza & - & - & Roja & 4 & $\begin{array}{c}\text { Nuche, } \\
\text { Garrapatas, } \\
\text { rosas } \\
\text { pálidas }\end{array}$ & N.E. \\
\hline $\mathrm{Me}$ & & & & & & & 3 & & \\
\hline
\end{tabular}

${ }^{\star}$ Me: Media (Fuente: el autor)

De acuerdo a lo reportado en la Tabla 3 la línea blanca del cuadro hemático nos muestra que dos individuos presentaron leucocitosis y linfocitosis, uno de estos también presento monocitosis y el otro animal y tres más eosinofilia, además uno de esos animales presento trombocitopenia, todos estos desordenes son causados 
más frecuentemente por agentes infecciosos bacterianos incluido rickettsias, virales y la eosinofilia problemas parasitarios. Para lo cual se recomendó realizar exámenes para determinar la presencia de enfermedades de origen viral más comunes (IBR, DVB, Leucosis), o bacterianas importantes como tuberculosis, brucelosis o paratuberculosis. Otras parasitarias como neospora, Ya con esos resultados analizar posibles descartes o tratamientos a los animales afectados. Que además pueden poner en riesgo la salud pública, dado el carácter zoonótico de algunos agentes patógenos.

Tabla 2. Análisis de sangre de los animales del IE El Dorado, Línea roja

\begin{tabular}{|c|c|c|c|c|c|c|c|c|c|}
\hline Parámetros & ERITROCITOS (M/pL) & НCT (\%) & $\begin{array}{l}\mathrm{HGB} \\
(\mathrm{g} / \mathrm{dl})\end{array}$ & VCM (fL) & $\begin{array}{l}\mathrm{MCH} \\
(\mathrm{pg})\end{array}$ & $\begin{array}{l}\text { MCHC } \\
\text { (gidL) }\end{array}$ & RDW (\%) & RETIC (\%) & $\begin{array}{l}\text { RETIC } \\
(\mathrm{K} / \mathrm{L})\end{array}$ \\
\hline $\begin{array}{l}\text { Rango de } \\
\text { referencia }\end{array}$ & $4.47-9.35$ & $22.5-39.9$ & $7.4-12.8$ & $40.4-56.4$ & $11.5-18.5$ & $30.2-33.5$ & $20.0-35.9$ & & $0.0-3.9$ \\
\hline Animal 1 & 6,13 & 24,4 & 8,4 & 39,8 & 13,7 & 34,4 & 26,2 & 0,1 & 3,1 \\
\hline Animal 2 & 5,92 & 24,5 & 8,4 & 41,4 & 14,2 & 34,3 & 25,7 & 0 & 2,4 \\
\hline Animal 3 & 6,59 & 28,5 & 9,6 & 43,2 & 14,6 & 33,7 & 27 & 0 & 1,3 \\
\hline Animal 4 & 6,26 & 26 & 9,4 & 41,5 & 15 & 36,2 & 27,7 & 0,1 & 3,1 \\
\hline Animal 5 & 5,91 & 28,9 & 9,3 & 48,9 & 15,7 & 32,2 & 25,3 & 0 & 2,4 \\
\hline Animal 6 & 9,56 & 39,4 & 11,8 & 41,2 & 12,3 & 29,9 & 38,1 & 0 & 3,8 \\
\hline Me & 6,72 & 28,6 & 9,48 & 42,6 & 14.3 & 33,4 & 28.3 & 0,03 & 2,68 \\
\hline$\sigma$ & 1,40 & 5,62 & 1,24 & 3,23 & 1,17 & 2,16 & 4,86 & 0,05 & 0,85 \\
\hline
\end{tabular}

${ }^{*}$ Me: Media; * $\sigma$ : Desviación estándar. Fuente: El autor

En la química sanguínea (Tabla 4) observamos que todos los animales presentaron glucosa (GLU) baja, igualmente globulinas (GLOB) altas, 5 animales presentaron tiempo de protrombina (TP) alto, 2 animales tenían bajo el calcio (CA), otros 2 la lipasa (LIPA) baja, y dos más tenían la amilasa (AMYL) alta, uno tenía el fosforo (PHOS) alto y otro el nitrógeno ureico en sangre (BUN) bajo. Estos desordenes metabólicos pueden ser de origen alimenticio, productivo, infeccioso o de varios, la disminución de la glucosa se puede deber a que los animales no comían la cantidad de alimento suficiente o que los nutrientes del forraje son bajos en energía, por esta misma razón se puede explicar la presencia elevada de la amilasa en algunos animales, debido a que el forraje es muy fibroso, se libera más cantidad de enzima para degradar más los carbohidratos no estructurales y aumentar la disponibilidad de glucosa. Para lo que se recomienda dar más alimento a partir de forrajes más 
tiernos o suplementación con sorgo o silo de maíz. Las globulinas nos explican la presencia de enfermedades infecciosas y problemas hepáticos, los animales que presentan estos problemas con las globulinas altas también indican disminución en el tiempo de protrombina y un animal alto el BUN, lo cual indica una posible afección al hígado en varios animales, lo que se recomendó fue analizar el probable uso de medicamentos o intoxicaciones por plantas a estos animales o evaluar que esto se deba a un problema infeccioso y realizar otras pruebas. Como ultimo también se encontró un animal con un desbalance en la relación calcio-fósforo, probablemente por baja disponibilidad de minerales en suelos, forrajes y sales, para lo cual se recomienda profundizar en el diagnóstico y suplementar en forma adecuada estos minerales acompañados de una suplementación con Vitamina D.

Tabla 3. Análisis de sangre de los animales del IE El Dorado, Línea blanca

\begin{tabular}{|c|c|c|c|c|c|c|c|c|c|c|c|c|c|c|c|}
\hline Parámetros & $\begin{array}{c}\text { Leucocitos } \\
\mathrm{K} / \mu \mathrm{L}\end{array}$ & $\begin{array}{l}\text { NEU } \\
\%\end{array}$ & $\underset{\%}{\mathrm{LYM}}$ & $\underset{\%}{\text { MONO }}$ & $\begin{array}{c}\text { EOS } \\
\%\end{array}$ & $\begin{array}{c}\text { BASO } \\
\%\end{array}$ & $\begin{array}{l}\mathrm{NEU} \\
\mathrm{K} / \mu \mathrm{L}\end{array}$ & $\begin{array}{l}\mathrm{LYM} \\
\mathrm{K} / \mu \mathrm{L}\end{array}$ & $\begin{array}{c}\text { MONO } \\
\mathrm{K} / \mu \mathrm{L}\end{array}$ & $\begin{array}{l}\text { Eos } \\
\mathrm{K} / \mu\end{array}$ & $\begin{array}{l}\text { BASO } \\
\mathrm{K} / \mu \mathrm{L}\end{array}$ & $\begin{array}{l}\mathrm{PLQ} \\
\mathrm{K} / \mu \mathrm{L}\end{array}$ & $\begin{array}{c}\text { MPV } \\
\mathrm{fL}\end{array}$ & $\begin{array}{c}\underset{P D W}{\mathrm{PDW}} \\
\mathrm{fL}\end{array}$ & $\begin{array}{l}\mathrm{PCT} \\
\%\end{array}$ \\
\hline $\begin{array}{l}\text { Rango de } \\
\text { referencia }\end{array}$ & $2.71-17.76$ & & & & & & $\begin{array}{l}0.68- \\
6.94\end{array}$ & $\begin{array}{l}1.20- \\
10.62\end{array}$ & $\begin{array}{l}0.02- \\
2.17\end{array}$ & $\begin{array}{l}0.01- \\
1.23\end{array}$ & $\begin{array}{l}0.00- \\
0.04\end{array}$ & $\begin{array}{l}147- \\
663\end{array}$ & $\begin{array}{l}5.9- \\
8.2\end{array}$ & $\begin{array}{l}6.0- \\
10.1\end{array}$ & $\begin{array}{l}0.12- \\
0.42\end{array}$ \\
\hline Animal 1 & 9,02 & 19,6 & 59,4 & 11,1 & 9,9 & 0 & 1,77 & 5,36 & 1 & 0,89 & 0 & 234 & - & - & - \\
\hline Animal 2 & 7,8 & 12,7 & 58,6 & 12,3 & 16,4 & 0 & 0,99 & 4,57 & 0,96 & 1,28 & 0 & 115 & - & - & - \\
\hline Animal 3 & 13,42 & 14,4 & 63,3 & 9 & 13 & 0 & 1,93 & 8,49 & 1,25 & 1,75 & 0 & 312 & 6,3 & 8,1 & 0,2 \\
\hline Animal 4 & 6,34 & 27,3 & 50 & 7,4 & 15 & 0,3 & 1,73 & 3,17 & 0,47 & 0,95 & 0,02 & 187 & - & - & - \\
\hline Animal 5 & 20,08 & 10,5 & 72,9 & 5,8 & 10,8 & 0 & 2,1 & 14,64 & 1,16 & 2,17 & 0,01 & 271 & 8,4 & 13,1 & 0,23 \\
\hline Animal 6 & 22,42 & 21,1 & 61,6 & 12,3 & 1,8 & 0 & 4,73 & 13,86 & 2,75 & 1,07 & 0,01 & 307 & - & - & - \\
\hline $\mathrm{Me}$ & 13,8 & 17,6 & 60,9 & 9,65 & 11,1 & 0,05 & 2,20 & 8,34 & 1,26 & 1,35 & 0,006 & 7,35 & 7,35 & 10,6 & 0,21 \\
\hline$\sigma$ & 6,72 & 6,24 & 7,43 & 2,70 & 5,19 & 0,12 & 1,29 & 4,89 & 0,77 & 0,50 & 0,008 & 76,2 & - & - & - \\
\hline
\end{tabular}

*Me: Media; * $\sigma$ : Desviación estándar. Fuente: El autor

En relación a los análisis de parásitos internos se encontró individualmente que solo dos de los 6 animales presentaban una parasitosis leve por Strongylidae spp y por Paraphistomidae spp, También se encontró una mayor prevalencia del hemoparásito Anaplasma spp, afectando a 4 de los 6 animales muestreados.

Para el tratamiento contra parásitos gastrointestinales se recomendó la administración de desparasitantes que contengan albendazol y/o prazicuantel, 
(Pérez et al., 2009) igualmente la realización de una cuarentena a los animales nuevos que ingresen, con muestreo de materia fecal y sangre, y la elaboración de un plan de un plan de desparasitación a los terneros.

Tabla 4. Bioquímica sanguínea de los animales del IE EI Dorado

\begin{tabular}{|c|c|c|c|c|c|c|c|c|c|c|c|c|c|c|c|c|c|}
\hline $\begin{array}{l}\text { Parámet } \\
\text { ros }\end{array}$ & $\begin{array}{l}\text { GLU } \\
\text { mgddL }\end{array}$ & $\begin{array}{l}\text { CREA } \\
\text { mgidL }\end{array}$ & $\begin{array}{l}\text { BUN } \\
\text { mgldL }\end{array}$ & BUNCREA & $\begin{array}{l}\text { PHOS } \\
\text { mgidl }\end{array}$ & $\begin{array}{c}\mathrm{CA} \\
\mathrm{mg} / \mathrm{dL}\end{array}$ & $\begin{array}{l}\text { TP } \\
\text { gidl }\end{array}$ & $\begin{array}{l}\text { ALB } \\
\text { gld }\end{array}$ & $\begin{array}{l}\text { GLOB } \\
\text { gidl }\end{array}$ & $\begin{array}{l}A L B / G \\
L O B\end{array}$ & $\begin{array}{l}\text { ALT } \\
\text { UL }\end{array}$ & $\begin{array}{c}\text { ALKP } \\
\text { ULL }\end{array}$ & $\begin{array}{l}\text { GGT } \\
\text { UL }\end{array}$ & $\begin{array}{l}\text { TBIL } \\
\text { mg/dl }\end{array}$ & $\begin{array}{l}\mathrm{CHOL} \\
\text { mgidl }\end{array}$ & $\begin{array}{c}\text { AMYL } \\
\text { UIL }\end{array}$ & $\begin{array}{l}\text { LIPA } \\
\text { UL }\end{array}$ \\
\hline $\begin{array}{l}\text { Rango de } \\
\text { referencia }\end{array}$ & $\begin{array}{l}56- \\
88\end{array}$ & $0.5-1.6$ & $10-25$ & & $4.0-8.6$ & $\begin{array}{l}8.0- \\
12.0\end{array}$ & $\begin{array}{l}62- \\
8.0\end{array}$ & $25-3.5$ & $30-4.9$ & & & $\begin{array}{l}28- \\
233\end{array}$ & $0-87$ & $00-0.7$ & $45-200$ & $0-34$ & $\begin{array}{l}30- \\
200\end{array}$ \\
\hline Animal 1 & 23 & 1 & 14 & 14 & 6,4 & 8,1 & 8,8 & 2,6 & 6,3 & 0,4 & 53 & 78 & 17 & 0,6 & 147 & 33 & 23 \\
\hline Animal 2 & 31 & 0,7 & 10 & 14 & 6,3 & 7,9 & 8,6 & 2,5 & 6,1 & 0,4 & 52 & 274 & 21 & 0,3 & 130 & 35 & 31 \\
\hline Arimal 3 & 23 & 0,8 & 15 & 19 & 7,1 & 8,3 & 8,3 & 27 & 5,6 & 0,4 & 52 & 49 & 14 & 0,6 & 139 & 36 & 39 \\
\hline Animal 4 & 24 & 0,9 & 13 & 14 & 8,7 & 7,7 & 8,8 & 2,6 & 6,2 & 0,5 & 41 & 101 & 23 & 0,3 & 115 & 34 & 39 \\
\hline Animal 5 & 10 & 1,1 & 10 & 9 & 7,5 & 8 & 8,7 & 2,5 & 6,1 & 0,4 & 43 & 147 & 19 & 0,3 & 108 & 33 & 21 \\
\hline Animal 6 & 39 & 0,8 & 5 & 6 & 8,6 & 9,4 & 7,9 & 2,9 & 5 & 0,6 & 27 & 157 & 16 & 0,3 & 82 & 32 & 70 \\
\hline $\mathrm{Me}$ & 25 & 0,88 & 11,1 & 12,6 & 7,43 & 8,23 & 8,5 & 2,63 & 5,88 & 0,45 & 44,6 & 134,3 & 18,3 & 0,4 & 120,1 & 33,8 & 37,1 \\
\hline$\sigma$ & 9,65 & 0,14 & 3,65 & 4,54 & 1,04 & 0,60 & 0,35 & 0,15 & 0,49 & 0,08 & 10,0 & 79,6 & 3,32 & 0,15 & 23,6 & 1,47 & 17,8 \\
\hline
\end{tabular}

${ }^{*}$ Me: Media; ${ }^{*} \sigma$ : Desviación estándar poblacional. Fuente: El autor

Sin embargo, para la problemática de rickettsias (Anaplasma spp) se aconsejó primero el tratamiento contra las garrapatas que son los transmisores de este hemoparásito, luego si el uso adecuado de tetraciclina, acompañado de dipropionato de imidocar, con terapia de sostén con hierro, vitamina B12 (Bernal, 2007) o de manera más practica la administración alguna formulación con diaminazene en combinación con oxitetraciclina para el control de los hemoparásitos, y que además incluya cianocobalamina, que resulta ser un buen precursor de glóbulos rojos y favorecería a contrarrestar la anemia si se presentara.

En el análisis de aguas se observaron anormalidades en los parámetros microbiológicos encontrando una elevada carga de coliformes totales y E. coli, lo cual es indicativo aguas contaminadas, debido a que estas aguas son obtenidas de la vega del rio Ariari; como medida de corrección se recomienda la desinfección con cloro a 1 ppm o la instauración de un filtro antes de la llegada al bebedero.

Los suelos en esta región son oxisoles, por su color característico rojo y alta presencia de hierros e hidróxidos de aluminio; son suelos de contextura franco 
arenosos, con múltiples deficiencias, pero las más importantes son la materia orgánica, pH y el porcentaje de nitrógeno total, lo cual es indicativo de baja calidad, debido a que su fertilidad es baja y además la fijación de nitrógeno en el suelo no es buena, esto debido en parte, a que estos suelos no han sido manejados adecuadamente y que las pasturas que se encuentran disponibles para la alimentación de los bovinos en tales condiciones no son de buena calidad, debido a que no aportan los nutrientes necesarios para los animales, por lo que se recomienda labores de enmiendas aplicando: Nitrógeno de 50 a $70 \mathrm{~kg} / \mathrm{ha}$, fósforo (como $\mathrm{P}_{2} \mathrm{O}_{5}$ ) de 25 a $50 \mathrm{~kg} / \mathrm{ha}$, potasio $\left(\right.$ como $\mathrm{K}_{2} \mathrm{O}$ ) de 25 a $50 \mathrm{~kg} / \mathrm{ha}$, y se recomienda NO ENCALAR.

Sumado a esto la implementación de sistemas agrosilvopastoriles para aumentar la materia orgánica y nutrientes que favorezcan a mejorar la calidad del suelo, y así poder introducir pastos mejorados para incrementar el rendimiento y valor nutritivo del forraje y la realización de bancos forrajeros y suplementos como elementos básicos para mejorar la productividad ganadera (Contexto Ganadero, 2015).

Con respecto a los estándares en buenas prácticas en alimentación bovina propuestos por el ICA, observamos que los suplementos alimenticios como la sal contaban con su registro sanitario ICA, el silo que se les administraba era almacenado en unas bodegas, pero no contaban con condiciones adecuadas de temperatura y humedad, para lo cual se le aconsejo cambiar el sitio de almacenamiento o adaptar mejor el que ya tienen, no utilizaban alimentos que provinieran de otros animales, los abonos que manejaban para nutrir los suelos eran orgánicos y trabajados por los estudiantes, aunque no aportaban suficientes nutrientes para el suelo. El agua utilizada para el consumo animal era de mala calidad microbiológica, poseían una baja disponibilidad y más en las épocas de verano y el acceso a los bebederos si era permanente. Se realizo una recomendación, en la cual debían periódicamente realizar análisis a los suelos para hacer las correctivas enmiendas y fertilización de los cultivos forrajeros. Realizar los análisis de aguas para evaluar la calidad microbiología. Igualmente se recomienda realizar un análisis bromatológico para evaluar la composición de los forrajes y 
conocer los nutrientes que contiene el material para formular raciones que satisfagan los requerimientos nutricionales de los animales.

\section{CONCLUSIONES}

En este proyecto nos enfocarnos en las tres variables (suelo-planta-animal) y su relación en un sistema de producción bovina en el instituto educativo El Dorado, mediante la implementación de las buenas prácticas ganaderas, garantizando el adecuado manejo y fortalecimiento de la parte de sanidad e inocuidad alimentaria.

La variable alimentación, para su correcto funcionamiento depende de que el animal se encuentre en buen estado de salud para aprovechar al máximo los nutrientes; que los alimentos estén en una cantidad adecuada para cubrir sus necesidades y que sean de buena calidad para suplir los requerimientos nutricionales.

La evaluación clínica de los animales del colegio permitió determinar problemas de sanidad que desfavorecen de cierta manera el aprovechamiento de los alimentos, y no solo eso sino la integridad del animal y de las personas que trabajan con ellos, Con respecto a la disponibilidad del alimento el colegio contaba con un área adecuada de potreros y establos para el mantenimiento de biomasa para la alimentación de los animales que tenían, y además contaban con suplementación de sal y silo de maíz, pero en calidad de nutrientes a pesar de que no se pudo realizar un análisis bromatológico, el análisis de suelo y la condición corporal de los animales nos demostró que estos pastos eran de baja calidad, un forraje muy lignificado y carecía de nutrientes que no cumplían las necesidades de los bovinos, esto genera una caída en los índices productivos, reproductivos y se refleja en animales con una baja condición corporal. A pesar de aplicar de las Buenas Prácticas en Alimentación Bovina, les falta algunos puntos indispensables para garantizar mejoras en la producción y otros factores, ellos contaban que al ser un colegio subsidiado por el estado carecen algunas veces de insumos como suplementación y medicamentos que no llegan en los tiempo adecuados, lo cual hace que cumplir con esos propósitos sea más difícil, para lo cual se les recomendó a campesinos, estudiantes y profesores a aplicar otras alternativas como la 
conservación de forrajes como el ensilaje, que favorezcan a mejorar sus índices productivos.

\section{REFERENCIAS BIBLIOGRÁFICAS}

1. Cadena, J., Mateus G. En nuche: vida y control. Instituto Colombiano Agropecuario, p 1-5. 1973.

2. Congreso de la Republica de Colombia. Ley 1753 de 9 de junio de 2015. Disponible En: www.secretariasenado.gov.co/senado/basedoc/ley 1753 2015.html

3. Contexto Ganadero. Ganadería Sostenible. 2015. Disponible En: https://www.contextoganadero.com/ganaderia-sostenible/la-importancia-de-larelacion-suelo-planta-animal-en-la-ganaderia

4. Corpoica. Cultivos para alimentación en sistemas de producción bovina de la Orinoquia Colombiana. Boletín técnico N. 44, 26. 2010.

5. Etter A., Zuluaga A. Áreas aptas para la actividad ganadera en Colombia. Bogotá D.C. Áreas aptas para la actividad ganadera en Colombia. 2018. Disponible En: http://reporte.humboldt.org.co/biodiversidad/2017/cap4/403/\#seccion4

6. Federación Colombiana de Ganaderos (FEDEGAN). Buenas prácticas ganaderas. 2010. Disponible En: https://www.fedegan.org.co/buenas-practicas-ganaderas

7. Gaviria X., Sossa C., Montoya C., Chara J., Lopera J., Córdoba C., Barahona R. Producción de carne bovina en sistemas silvopastoriles intensivos en el trópico bajo. $2012 . \quad$ Disponible En: www.researchgate.net/profile/Rolando Barahona Rosales/publication/262936613 Produccion de Carne Bovina en Sistemas Silvopastoriles Intensivos en el Tropico Bajo Colombiano/links/Odeec539695ec91961000000/Produccion-deCarne-Bovina-en-Sistemas-Silvopastoril

8. Gonzales, J. Pastoreo racional Voisin, eficiencia y sostenibilidad. Ministerio de Agricultura y Ganadería MAG. 2014. Disponible En: www.mag.go.cr/bibliotecavirtual/drocc-hoja-divulgativa17-2014.pdf

9. Iglesias J., Funez J., Oldalys T., Milera M. Diseños agrosilvopastoriles en el contexto de desarrollo de una ganadería sustentable. Pastos y Forrajes, 34 (3). 2011.

10. Instituto Colombiano Agropecuario (ICA). Buenas prácticas en alimentación animal. Ficha técnica. 2008. Disponible En: www.ica.gov.co/getdoc/2613a184-3bd9-4176a605-59597dd12253/publicacion-31.aspx

11. Olguin A., Bernal. Clínica de los bovinos 1, anaplasmosis. Universidad Autónoma de México. 2007. Disponible En: www.ammveb.net/clinica/anaplasmosis.pdf

12. Pardini A. Perspectiva sobre la valorización de los sistemas agrosilvopastoriles en la cuenca del Mediterráneo. Pastos y forrajes, 30 (1). 2007.

13. Pérez J., Diaz M., Pérez A., Ferrere F., Monje B., Norman F., López R. Tratamiento de las enfermedades causadas por parásitos. Unidad de Medicina Tropical, Servicio de Enfermedades Infecciosas, Hospital Ramón y Cajal, Madrid, España, 28 (1): 44-59. 2009.

14. Rocha, F. Bouda, J. Fisiopatología de las deficiencias de cobre en rumiantes y su diagnóstico. Revista Veterinaria México, 32 (4): 289-296. 2001. 